\title{
Volume Morto: performance e corporeidade
}

\author{
Eloísa Brantes Mendes, ${ }^{I, \star}$ Maurício da Silva de Lima, ${ }^{I I}$ Ana Paula Ferrari Emerich, ${ }^{I}$ Thaís Leitão Chilinque \\ ${ }^{I}$ Univerisdade do Estado do Rio de Janeiro, Rio de Janeiro, RJ, Brasil \\ ${ }^{I I}$ Universidade Federal do Rio de Janeiro, Rio de Janeiro, RJ, Brasil
}

\begin{abstract}
Resumo
O processo de pesquisa e criação do espetáculo Volume Morto é o campo de partida deste relato sobre performance, memória corporal e relações estético-politicas implicadas na trajetória artística do Coletivo Líquida Ação desde 2007. A presença da água como elemento vital, utilizada nas performances de intervenção urbana, faz parte da proposta artística deste coletivo que problematiza as fronteiras entre visibilidades e invisibilidades da cidade habitada. A água, ligada às múltiplas temporalidades da experiência corpo-espaço na ação performática, também vai ao encontro das práticas de convívio e produção artística, voltadas para a sustentabilidade do próprio coletivo como espaço de pesquisa independente.
\end{abstract}

Palavras chave: performance; corporeidade; memória; água e montagem.

\section{Dead volume: performance and corporeity}

\begin{abstract}
The process of research and creation of the show Dead Volume is the starting point of this report on performance, body memory and aesthetic-political relations implied in the artistic trajectory of the Coletivo Líquida Ação since 2007. The presence of water as a vital element, used in the performances of urban intervention, is part of the artistic proposal of this collective that problematizes the boundaries between visibilities and invisibilities of the inhabited city. Water, coupled with the multiple temporalities of body-space experience in performance acting, is also in line with the practices of socializing and artistic production, geared towards the sustainability of the collective itself as an independent research space..
\end{abstract}

Keywords: performance; corporeity; memory; water and composition.

O processo de pesquisa e criação do espetáculo Volume Morto, realizado pelo Coletivo Líquida Ação é o campo de partida deste relato sobre performance, memória corporal, processos de montagem e relações estético-políticas implicadas. A trajetória artística deste Coletivo formado em 2007 é marcada pela presença da água, utilizada em todas as performances e intervenções urbanas realizadas desde então. A presença da água como elemento vital é parte das performances que colocam em jogo processos de montagem entre corpo - água - espaço urbano, problematizando as fronteiras entre visibilidade e invisibilidade da cidade habitada. A água, ligada às múltiplas temporalidades da experiência corporal acionadas durante a performance, também passa pela relação entre maleabilidade e coletividade em nossas práticas de convívio e modos de produção artística. Este artigo escrito de forma fragmentada, e assinado por cada participante do processo Volume Morto, é uma oportunidade de pensar nosso coletivo a partir de heterogeneidades, que sem se misturarem de forma fusional por uma narrativa do coletivo como entidade autoral, mantem suas tensões criativas por relações de alteridade.

\section{Eloisa Brantes}

O Coletivo Líquida Ação, constituído por artistas de diversas áreas apresenta, desde seu início em 2007, uma grande circulação entre seus participantes e colaboradores. A estrutura de grupo, baseada na permanência das mesmas pessoas com funções definidas, não é a base dos nossos trabalhos coletivos. A circulação de pessoas e suas escolhas em participar ou não das performances, ficar ou

\footnotetext{
^Endereço para correspondência: Universidade do Estado do Rio de Janeiro. Rua São Francisco Xavier, $524-11^{\circ}$ andar /bloco E, sala 110. Maracanã, Rio de Janeiro, RJ - Brasil. CEP: 20550900.E-mail: elobrantes@gmail.com, maulima@ gmail.com, anapaulaemerich@gmail.com, thais.thaischilinque@gmail.com
}

partir, são constituintes do próprio coletivo como espaço político no qual o exercício da alteridade comporta diferenças e resistências ao tipo de organização hierárquica. Acordos e contrariedades muitas vezes produzem afastamentos críticos e proximidades incômodas que nos levam a refletir sobre o que estamos fazendo juntos. O desafio de trabalhar na ausência de consenso incorpora forças que desestabilizam nossas certezas gerando questões que mobilizam as performances. A delimitação e clareza das questões que se apresentam é um exercício de precisão intelectual, emocional, estética e ética que colocam em jogo a própria compreensão "do que estamos fazendo". Neste exercício, às vezes árduo e sempre estimulante de desconstrução de si na relação com o outro, a prática da performance nos oferece a instabilidade necessária à descoberta do que é comum para além do grupo de pessoas envolvidas, pois o comum inclui também nossas visões e relações com a vida da cidade em sua complexidade e heterogeneidade. Neste processo de pesquisa, em que o próprio "estar junto" é sempre questionado, seguimos a economia do desejo em "agenciamentos coletivos de enunciação" e fluxos de pensamento-ação. que deságuam pelo corpo. (GUATTARI; ROLNIK, 2005).

Nas performances de intervenção os usos da água intensificam a temporalidade da relação corpo - espaço em dois aspectos: as reações imediatas do corpo em contato com a água e o acesso à memória coletiva da água nas cidades. No cruzamento destas temporalidades distintas, ecoa o conceito de "ação em estado líquido", ou seja, uma ação maleável cujos fluxos, formas e percursos dependem dos suportes físicos e simbólicos do espaço, dos corpos envolvidos e das interações com os diversos contextos sociais e culturais que atuam sobre as 
performances. Neste sentido a corporeidade dos performers não é trabalhada como instrumento de expressão da linguagem cênica. Trata-se de uma corporeidade transpessoal, ou seja, um corpo-performer que transita por diferentes camadas de subjetividades produzidas no tempo-espaço constituinte da performance. Podemos pensar em uma corporeidade líquida cuja potência vital penetra nos ambientes, espacializando temporalidades distintas (o imediato, a memória, a duração, o instantâneo, a expectativa, a espera, etc.) por deslocamentos estéticos que reconfiguram as relações entre as coisas, corpos, lugares e imaginários em realidades dadas - a liquidez do corpo-performer entregue aos fluxos de movimentos que o atravessam. A questão da presença, aqui, não se coloca como consciência do corpo, mas como possibilidade de acessar fluxos que mobilizam as fronteiras entre o que está fora e o que está dentro do corpo individualizado. $\mathrm{O}$ contato com a alteridade pode ser visto como procedimento artístico das pesquisas em performance com o Coletivo Líquida Ação.

Trabalhando há alguns anos com performances em situação de intervenção urbana, começamos a perceber que a emergência de movimentos coletivos pode ser provocada pela dissociação entre sujeito e ação realizada. As interferências dos lugares e das pessoas são constituintes da ação. A imprevisibilidade da performance que sempre é coletiva quando se trata de intervenção urbana, gera um tempo/espaço que coloca em jogo os próprios limites do corpo em performance. Até que ponto nossas reações ao que acontece fazem parte do que sabemos de nós? A destituição do sujeito como único responsável pela ação realizada é importante na dinâmica processual, inclusiva e coletiva da performance de intervenção. Se trata de uma corporeidade líquida cujos fluxos de movimento descentralizam a dimensão expositiva do corpo como principal foco de atenção da performance. $\mathrm{O}$ caráter provocativo da performance de intervenção urbana demanda um mergulho do performer nas profundezas de sua própria pele em contato direto com a cidade. Corporeidade política que ao deslocar a ordem das relações existentes possibilita a emergência de outras realidades.

A pele-superfície de um corpo que, sendo penetrável pelo entorno, interfere na cidade na medida em que desestabiliza as fronteiras da linguagem artística. Nos deslocamentos estéticos provocados pela performance de intervenção, a decodificação "arte" pode ser redutora. A confusão entre diversos registros de percepção da realidade cria uma suspensão dos sentidos que é fundamental no caráter de intervenção da performance (RANCIÈRE, 2017). O performer não é apenas o artista, mas inclui todos que atuam e/ou são atuados pelo acontecimento. Em espaços públicos toda performance é política.

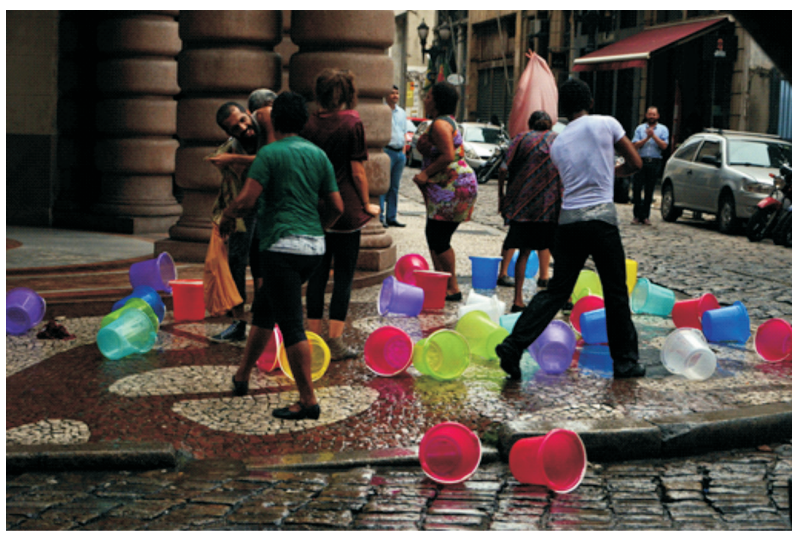

Paisagens Inter-Urbanas. Bienal SESC de Dança/ Santos, 2013. Foto: Lairton Alves.

\section{Somos $70 \%$ água!}

A crise hídrica que, em 2013, deflagrou a insustentabilidade das cidades em Estados bem desenvolvidos economicamente como São Paulo, Rio de Janeiro e Minas Gerais no sudeste brasileiro, foi o ponto de partida do processo de criação do espetáculo Volume Morto: uma referência direta ao uso das reservas hídricas vitais. Depois de nove anos atuando com água em espaços públicos e problematizando as fronteiras sociais, culturais e econômicas em torno da distribuição de água na produção da memória urbana, a violência da crise hídrica nos levou a questionar nossas ações de transportar água pela cidade. As mudanças no contexto social e político do país nos levaram para dentro de uma sala de ensaios. Diante da questão recorrente sobre "o que estamos fazendo juntos"? surgiu a necessidade de um recolhimento. As ações-intervenções em espaços públicos não poderiam nos provocar tanto quanto a entrada em uma sala de teatro, com todas as implicações políticas e institucionais que estão envolvidas neste "lugar da arte". Como levar a performance para uma sala de espetáculos? No modo como atuamos com a rua a relação com o espectador é maleável, instável e não pré-estabelecida como no teatro. Romper as convenções da representação teatral com a impermanência da performance se tornou um desafio.

A "inutilidade" da reserva de água é fundamental na dinâmica de funcionamento dos mananciais, pois nela se mantém todo o ecossistema da vida aquática. $\mathrm{O}$ consumo da água contida no volume morto pode causar danos irreversíveis ao meio ambiente. Mas durante a crise hídrica um acúmulo de fatores - o desespero da população, o despreparo dos governantes e gestores públicos em lidar com a "tragédia anunciada" pela sua própria ineficácia administrativa, e o sensacionalismo midiático em denunciar o desperdício de água pedindo para as pessoas economizarem seu consumo doméstico - dava mais importância à retirada da água do volume morto para ser usada, do que a sua permanência vital ao ecossistema. A inversão desta perspectiva utilitária das reservas foi o ponto de partida da criação do espetáculo baseado em diversos fragmentos de arquivos pessoais e coletivos como ativadores de nossas reservas de água-vida. 


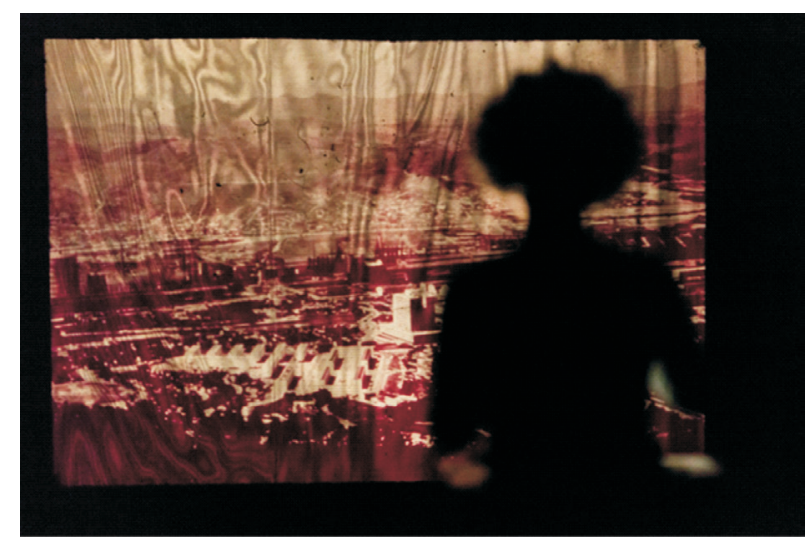

Volume Morto/ Sesc Copacabana 2016. Foto: Cícero Rodrigues.

Em 2015 começamos uma investigação artística sobre montagem e memória corporal no processo de criação do espetáculo Volume Morte. Nos colocamos o desafio de elaborar uma dramaturgia baseada na temporalidade da performance e sua potência transformadora. Como levar para o palco a potência transformadora das performances de intervenção, que lidam diretamente com as especificidades dos lugares em seus fluxos de movimento? Ou melhor, como lidar com as especificidades do palco inserindo todas as pessoas presentes no acontecimento cênico? Como trabalhar na elaboração de fragmentos a serem vistos pela totalidade de um espetáculo, ou seja, como fazer uma dramaturgia que não seja apenas expositiva? Como elaborar uma dramaturgia selvagem que mantenha as tensões da imprevisibilidade e desestabilize o lugar do espectador e do performer? Estas questões atravessaram o processo de pesquisa e criação do espetáculo entre 2015 e 2016. A investigação dos arquivos e a transformação destes materiais em ações e fragmentos de cena foram a base do espetáculo. Importante dizer que todos os objetos utilizados foram retirados do acervo do Coletivo Líquida Ação. A própria memória do coletivo estava em jogo nesta montagem que também era uma reciclagem. Um mergulho nas coisas que guardamos, o que fica em nós, a permanência da inutilidade: volumes mortos como potência de vida.

\section{Maurício Lima}

A trajetória individual dos artistas do Coletivo Líquida Ação tem um elemento comum. O caminho dos três artistas envolvidos diretamente na criação de Volume Morto é atravessado pelo teatro. O teatro, então, se apresenta como uma nova pesquisa espacial, para além de sua dimensão física e, sobretudo, enquanto linguagem.

Uma nova questão se apresenta: como levar a rua para um espaço fechado, aparentemente controlado, convencionado, sem entrar em uma representação da mesma? Como sair da rua sem abandoná-la?

Estar na rua é da ordem do descontrole, tudo pode acontecer. Isso motivava nossas criações, aquilo que não se pode calcular, prever. E onde é que habita o imponderável da sala fechada?

Durante todo o processo, que dura pouco mais de um ano, dia após dia, tentamos descobrir e inventar formas de manter a vida, o frescor, e o risco, dentro da repetição.
Alguns elementos dessa nova pesquisa pressupunham o ato de repetir. A repetição é uma das bases do teatro e da dança. Todo diretor, ator e bailarino, lida com esse elemento diariamente em suas criações e cada um tem sua própria forma de fazê-la. Para nós, enquanto coletivo, esse era um elemento novo, então precisávamos descobrir, criar formas de vida, dia após dia.

Quando se está na rua a alteridade se apresenta de forma bruta - o fluxo de pessoas, de carros, intervenções sonoras e visuais - a convenção artista $>$ público fica abalada, exigindo do performer um estado de presença extremo. Já no teatro essa alteridade se manifesta de forma diferente, talvez não tão direta pois está vestida com os "bons modos" da convenção teatral, mas igualmente forte.

Quando estávamos na rua, por vezes procuramos desaparecer, borrar o contorno da representação, fazer ver o invisível, nós íamos até o "público", agora o público vem a nós.

Volume Morto é parte de uma pesquisa de anos. Pode-se dizer que esse processo se iniciou antes de seu início. Ele foi tomando forma aos poucos - nas primeiras experimentações com texto em "Mitologias Urbanas Ouro Líquido", realizado no Festival de Inverno de Ouro Preto e Mariana, a partir de trechos da obra Marília de Dirceu do autor Tomás Antônio Gonzaga; nas primeiras construções dramatúrgicas envolvendo palavra, memória e movimento em "Rio Cruzeiro", performance realizada a partir da narrativas de moradores da Vila Cruzeiro acerca da ocupação do exército na favela em 2011 - ação realizada na própria favela e tendo como performers os próprios moradores; ao relacionamento intenso com o Sermão de Santo Antônio aos Peixes, do Padre Antonio Vieira, sendo essa a primeira palavra-ação que nos acompanha até aqui. Talvez o espetáculo Volume Morto seja a radicalização de uma pesquisa de anos, a fricção entre espaço público (rua) e espaço privado, movimento e palavra, indivíduo e coletivo, visibilidade e invisibilidade.

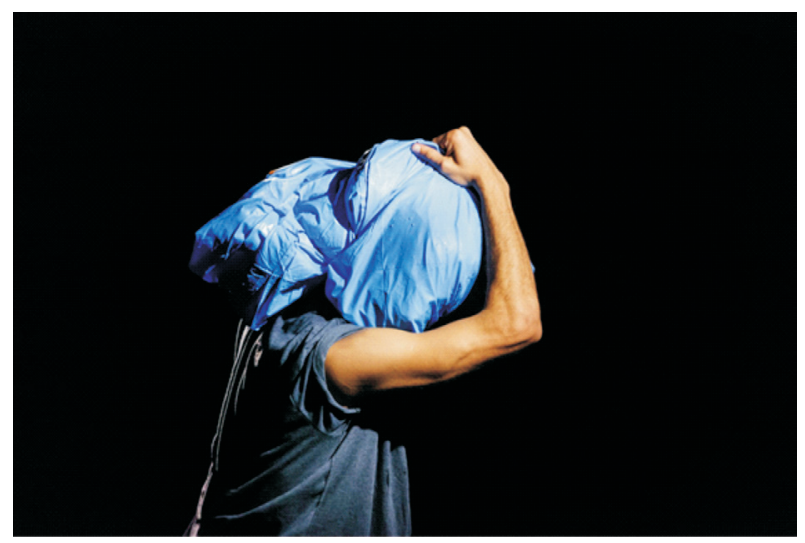

Volume Morto/ Sesc Copacabana 2016. Foto: Cícero Rodrigues.

O trabalho do coletivo é caracterizado por uma forte pesquisa plástica. A plasticidade constitui nosso pensamento ético-estético. Durante anos trabalhamos com um objeto específico: o balde. Desenvolvemos durante esse tempo toda uma pesquisa de movimento e de produção 
de sentidos, na relação corpo-objeto-espaço. O balde, às vezes em grande quantidade, às vezes em apenas uma unidade, era dispositivo para essa provocação estética.

Ao iniciarmos os ensaios de Volume Morto, nos colocamos algumas "regras", a primeira delas era a negação ao balde. Era preciso negar um elemento tão constituinte de nossas ações para saber onde nossos corpos - a única coisa que nos restava- poderia nos levar.

Partimos, então, com nossos corpos e toda a memória individual e coletiva que tínhamos, rumo a um rio sem margens.

A água agora, mais do que nunca, se apresenta como assunto urgente a nós. No auge da crise hídrica nacional, pensávamos em como seguir depois do fim da água. Atravessados por toda essa situação política, nos encontramos com o tão repetido "volume morto". O que é esse volume morto que todos os jornais estampavam? Volume morto é o nome dado a quantidade de água que fica abaixo dos canos de captação de uma represa. A água, que recebe este nome não deveria ser usada por se tratar de uma parte onde se concentram metais pesados. Mas, o que pouco se falou é que esse mesmo volume de água é indispensável para a vida e manutenção de todo um ecossistema existente ali.

\section{Dramaturgia Sustentável - formas de se fazer:}

A sociedade estimula o consumo desenfreado de notícias, de aparelhos celulares, de um feed de informação efêmero no Facebook - o novo em detrimento do velho. Fazendo com que tudo seja rapidamente descartado, descartável. Indo na contramão dessa "ordem social", o processo se coloca o desafio de trabalhar apenas com o consumo daquilo que já existe, acessando memórias pessoais e coletivas na tentativa de uma construção sem excessos. Na urgência do tempo não há espaço para prolixismo, é preciso dizer apenas o necessário antes que o tempo acabe.

Esse pensamento está para além de um fio condutor para construção da dramaturgia - a dramaturgia não está apenas ligada a construção de um texto, mas também à própria criação da cena, do movimento, da sonoridade - ou de apenas uma forma de baratear custos, mas essencialmente, como pensamento político e forma de trabalho do Coletivo Líquida Ação.

Num meio onde as condições de trabalho para o artista muitas das vezes são ínfimas, beirando o desrespeito nas relações com instituições, onde ele é o que menos ganha e aquele que recebe por último, buscamos um modo de trabalho onde o artista é o "bem mais precioso". Para isso, nesse processo, é importante lembrar a particularidade deste trabalho e do momento atual do Coletivo Líquida Ação. Priorizou-se um investimento maior no material humano ou, ao menos, mais equilibrado no âmbito do orçamental. Isso não é uma regra geral que se opõe a outras formas de trabalho, visto que, aqui, a forma não está separada do conteúdo.
As formas de financiamento para produção artística estão cada vez mais escassas. Não há, em nossa cidade, uma política cultural pública e privada consistente, que valorize a arte como bem comum e necessário, cultural e educacionalmente, como potencializador na construção de uma sociedade mais crítica. É preciso, então, subverter a ordem das coisas, e buscar um processo que não trabalhe a partir da falta, daquilo que 'poderíamos ter', seja em relação a tempo ou dinheiro. Mas, sim, trabalhar com aquilo que se tem. É preciso fazer uso das nossas reservas para transformação do velho em novo. Como o volume morto é uma grande concentração de vida, a nossa dramaturgia pensa a reciclagem, a multiplicação e transformação do que já existe, ao invés da produção de mais lixo. Fez-se necessário, em Volume Morto, ir ao encontro de si para conseguir encontrar o outro.

\section{Thaís Chilinque}

Concomitantemente à ostensiva divulgação da crise hídrica no Estado de São Paulo, veiculada pela grande mídia, recebemos a notícia da impossibilidade do uso da água na proposta de intervenção urbana, apresentada ao projeto de residência artística PERFORMANCE. ${ }^{1}$ Ao lidar com tal "impedimento" na ação coletiva de transportar água pela cidade, o grupo (re)afirmou a natureza de sua pesquisa e atualizou seu percurso de criação em performances no encontro com o fluxo dos acontecimentos. Como evocar a potência líquida, vital, imagética e sensorial do elemento água na sua ausência?

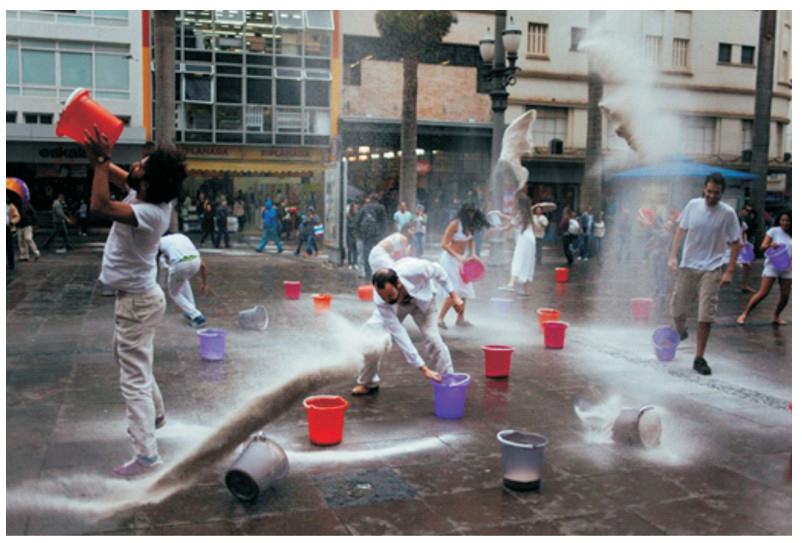

Residência artística PERFORMANCE / Sesc Campinas 2014.

Na ocasião, a escolha pelo elemento areia não era uma representação da falta d'água, mas a potência da água em sua ausência, modificando ações e linhas de força da proposta de intervenção. Considerando a mudança de peso, a areia modificou nossas relações com a gravidade e com a densidade das relações entre corpo e cidade. Ao verter grãos de areia, instaurou- se uma violência vertiginosa entre macro e microesferas; houve uma reconfiguração das tensões que se estabeleciam entre um grão de areia e a paisagem. Vazando as camadas mais internas da pele e do corpo, experenciamos um novo fundo tônico ligado à precisão, à atenção e à inteireza do movimento e de suas relações com outros corpos e espaços.

${ }^{1} \mathrm{Na} 99^{\mathrm{a}}$ Edição do evento PERFORMANCE (Sesc Campinas/ 2014), o coletivo realizou a performance Ser ou Não Peixe? e uma oficina que culminou na intervenção Paisagens Inter-Urbanas. 
A violência e velocidade gravitacionais atualizaram de maneira profunda movimentos de resistência imponderáveis. Não resistir era sucumbir - e ponto. A radicalidade dessas sensações trouxe à tona a lembrança da performance Ser ou Não Peixe? também realizada no Morro da Providência (Rio de Janeiro, 2012). A leitura molhada do sermão do transgressor Pr. Antônio Vieira inaugurou um mar eufórico de crianças que se divertiam em golpear água nos performers; o fim da "água limpa", cuidadosamente distribuída em baldes coloridos, trouxe uma enxurrada de água esverdeada na direção da ação. O texto de 1654 foi o dispositivo performático que detonou um encontro estético e político entre performers, as crianças, seus pais, traficantes e toda gente que ali estava; um encontro de realidades diversas e produção de uma realidade comum naquele espaço-tempo. ${ }^{2}$

A experiência de Campinas veio romper com a "ponderação" e a "condescendência", seja pelo viés da memória corporal, alienação e/ou hegemonia daquilo que nos afasta da experiência do corpo. Inauguramos o tempo da urgência e de uma economia do desejo, bem como o tempo da falência de modelos, de cidade, de reforma urbana, de como fazer arte; e até arte urbana, dita por muitos, como arte da espontaneidade, liberdade e da coisa pública. Foram mais de 12 meses de investimento e investigação. Naquele momento quais seriam as questões de gravidade para cada pessoa do Coletivo? Como produzir encontros afetivos e efetivos usando o caminho da arte? Como radicalizar, dentro do próprio grupo, aquilo que não é hierárquico e nem familiar no intuito de criar um espaço possível para o exercício da alteridade?

Beleza, nostalgia, salubridade, harmonia.... As cores dos baldes foram se distanciando e o olho foi perdendo sua dependência por uma exterioridade chapante; a atenção expandiu por uma "movência" complexa: interna-individual-privada-singular-subjetiva e externa-coletiva-pública-múltipla-institucional e individual-múltipla-pública-subjetiva e por aí vai. Sustentar o peso de sacos de areia, mergulhar e banhar-se nessa aridez do concreto não revelou o fundo, o fim e nem um lado, mas trouxe à tona o reservatório de vida, tridimensional, imensurável e imanente ao corpo. Volume Morto é um continuum da pesquisa do Líquida Ação que espirala, circula, dobra, verte, refrata, mergulha, toca, chacoalha, arrebenta, respira e muda de estado físico. Os procedimentos deste trabalho estão comprometidos com o espaço, com o que o compõe e o anima. Por isso pensar no trabalho de criação é pensar também em como viabilizá-lo financeiramente, dialogar com as instâncias monetárias, institucionalizadas e burocráticas. Investir na pesquisa é também experimentar um modo de fazer artístico inexorável à prática comercial: elaborar-performar-produzir. Desde o início do grupo, foi criado um "caixa". A venda de um projeto corresponde a investir nesse caixa, um valor equiparado aos cachês e serviços. Um valor comum ao coletivo que o alimenta, numa dig-

\footnotetext{
${ }^{2}$ Em 2012, a Secretaria de Habitação do Município do Rio de Janeiro marcou com "SMH" centenas de casas que seriam demolidas para a implantação do teleférico da Providência. Além de demolir a Praça Américo Brum- um espaço importante para a comunidade- a SMH conseguiu desapropriar cerca de 200 famílias.
}

nidade ética do trabalho e das relações. Com o caixa do coletivo, conseguimos manter alguma independência do mercado da arte. $\mathrm{O}$ trabalho construindo o seu próprio tempo de autonomia e dedicação.

Na construção do espetáculo, objeto dessa escrita, o volume morto do Sistema Cantareira ativou memórias, desejos e inquietação dessa água que nos une. Na sala de ensaio procuramos traçar a localização "geográfica" dos corpos; (re)conhecer as pessoas com as quais trabalhamos; entender se o que estávamos fazendo na rua ainda fazia sentido. Partimos de um ambiente rarefeito e árido para tocar (nossos) volumes. Quando o texto do Fernando Reinach (2014) chegou em nossas mãos, reafirmamos as potencialidades e vitalidades dos volumes mortos. O processo acessou um espaço liminar entre a nossa memória e a memória do mundo, entre a liquidez das nossas vontades e "limitações" e vontades e "limitações" do mundo.

Asfixia e desconforto acompanharam o processo. Era preciso estranhar; transformar o familiar em exótico (e vice-versa) para conseguir mergulhar, ultrapassar a fase umbilical e expandir a noção de indivíduo. Esse atravessamento só foi possível por uma ética e confiança construída entre nós durante os seis anos de trabalhos juntos. O trabalho tinha a ver com (re) inventar mundos, num processo incessante de esquecer e lembrar. O medo e vulnerabilidade estavam presentes diante de um "fim"; do fim de uma imagem de si, do outro e daquilo que até então conhecemos como "nosso mundo". A ficção teve um peso nesse processo; ficcionar para multiplicar, sobrepor, acumular e reconfigurar realidades. Não era nosso objetivo determinar um caminho, polarizar discursos, dar a direção para uma humanidade salutar. Seria ingênuo e alienado pensar em ocupar apenas um lado da história. Acessar as lógicas da sociedade de consumo e do capital financeiro era acessar a complexidade e controvérsias da nossa própria existência. A ideia era duvidar, deslocar e estranhar; refletir e fazer refletir; colocar em jogo nossos próprios contornos e, quem sabe, fundar outros contornos possíveis. O mergulho na rua da pele trouxe o que era excessivo, o que sobrava no nosso imaginário e cotidiano, diante de um país que vivia a iminência de um golpe de Estado. Entrar na caixa-preta, naquele momento, era questionar a vida em sua forma intensiva, espetacular, efêmera e vulnerável.

Em abril de 2015 éramos 5; ficaram 3 e depois 4. Sempre na reserva e na urgência ordinárias. Era uma construção de espetáculo repleta de volumes de diferentes naturezas: poluições e transposições de rios para alimentar metrópoles; formas de violência urbana por questão de gênero, desejo sexual, religião e cor da pele; crises para controlar a cólera do mercado financeiro; corpos vivos e mortos que desapareciam; os sistemas de cárceres; investimentos do Estado na desigualdade social; burocratizações da vida; a sacralização do consumo para alienar a classe trabalhadora; fomento da impotência, ceticismo e melancolia; correntes de imigrantes rumo à Europa. Protegidos por um romantismo burguês, observávamos, 
no horizonte, "o fim" e, como dizia Eloísa, estávamos nos dedicando a viver "futuros passados", excitados com a ideia de um progresso.

A criação do espetáculo se desenvolveu simultaneamente ao projeto homônimo que seria realizado em três cidades no curso do Rio Doce. Eloísa, Ana Paula e Cau (produtora) submeteram, a partir da pesquisa do Líquida Ação, o projeto de residência artística Volume Morto. Em 5 de novembro de 2015, três dias depois de submeter a proposta, essa matéria de vida e criação se misturou à lama tóxica da Samarco. O Rio Doce, que alimentava a região de maior biodiversidade do planeta, tinha sido exterminado num duro golpe. Para nossa surpresa, fomos aprovados no edital, o que se revelou como um grande desafio. O que surge da água- lama? O que fazer depois do fim? Qual é o uso que fazemos das nossas reservas? Viver a intensidade desse luto radicalizou nossas posturas como performer e seres humanos.

A direção do espetáculo estava comprometida em evitar o voyerismo. O acesso biográfico à lógicas predatórias, como procedimento de fricção espacial e temporal, era um convite de acesso à reserva energética e à matéria que nos constitui, no que se refere tanto ao artista como ao espectador. Essa fricção produziu a ação de rolar continuamente pelo chão. Rolávamos na Casa da Glória, no Centro Coreográfico, no Laurinda, no Sesc, não tínhamos mais a mesma referência. Volumes movidos e moventes por uma coluna metálica imaginária e horizontal. Os corpos pereciam como em fornos de padarias, porões de navios, presídios, leitos de hospitais, e orfanatos. $\mathrm{O}$ enjoo vinha de uma ação paradoxal de passividade e agência combinadas; permitiu instaurar o "milagre da multiplicação": o ruído das referências pessoais e coletivas detonaram uma polifonia cênica que nos interessava.

"Quantos somos?" É a questão que sempre retorna e nos localiza no tempo-espaço. O volume é uma abstração, mas nos auxilia a tocar nas forças que nos fazem mover. Durante a maior parte do tempo, éramos apenas três. Fora a direção, um homem e uma mulher em cena. Como criar um espetáculo sem resumi-lo ao universo particular? As individualidades e tensões interpessoais se apresentaram. Não havia rota de fuga. O tempo era urgente e atravessado. Por isso, o rigor nos procedimentos. Investimos nas potencialidades dos volumes mortos- não pela via do ressentimento na iminência do fim- mas pela via da alegria em acessar a reserva de maior concentração e potência criativa. Das improvisações, surgiram fragmentos, gestos e textos que compuseram uma dramaturgia acidentada por forças coexistentes e que complexificaram a abordagem de questões como o cuidado com o meio ambiente, o machismo e o racismo. A violência física e psíquica impelida aos corpos lançou um movimento vertiginoso de estar sempre dentro e fora das situações, num marejar das estruturas já conhecidas.

Esse modo de implicação com o trabalho e com a vida trouxe, sem dúvida, uma outra maneira de "estar junto" mais plural, coletiva, responsável, vulnerável, afetiva, horizontal e autônoma. Performar objetos, textos e ações do acervo do coletivo e do acervo pessoal criou uma tensão entre o que conhecíamos (e até desejávamos manter) e um amórfico "devir" das coisas. Vazamos a visualidade e sentidos cotidianos para escutar essas ações em sua polifonia, numa conversa rica e inquietante entre os artistas que compuseram a equipe do espetáculo, o público e os colaboradores. Numa multiplicação de vozes, silêncios e ruídos, surgiram estranhamentos potentes que reconfiguraram os afetos, as produções artísticas e os procedimentos para manter vivo o trabalho de pesquisa e criação artística em performance.

\section{Ana Emerich}

Um breve desvio acerca da escuta dos rios, da voz de suas fontes e do tempo visual: Volume Morto coloca para a percepção uma dimensão temporal relativa, não somente ao passar do tempo, mas também às marcas visíveis que as ações imprimem no espaço, com a memória do tempo. Traz uma gama de sonoridades entrelaçadas - dos sons de água à voz humana, dos sons de objetos à materiais de arquivo - em gestos visuais e faixas compostas a partir destes elementos. Há um espectro de ações poéticas que percorre e contamina os contornos de uma experiência cênica que pensa a carne da terra. O corpo que carrega um rio não é um corpo perene, o corpo do humano não é um corpo ingênuo e um corpo em processo de criação não é um corpo neutro. Todo corpo é político por isso.

\section{Pausa}

Atelier da Escuta é uma proposta de acompanhamento de projetos que desenvolvo junto à artistas e instituições em módulos de colaboração. Pensar o som como lugar permeado de imagens latentes, não retinianas. Entender as vozes humanas e as vozes diversas como uma porção intangível do espaço e que são, elas mesmas, corpo. Pensar as sonoridades e o volume arquitetônico junto à dramaturgias do cotidiano ou em contextos cênicos, e o tempo como uma prática de expansão: plataforma para emergência de polifonias heterogêneas.

O convite e os encontros com o Coletivo Líquida Ação trouxeram uma dobra à esta pesquisa. Especificamente, considerar a dimensão sônica das ruas e o contorno acústico de uma sala de teatro abre uma investigação acerca de encontros e também de passagens. Imprime um certo ritmo e contaminações ao percurso desde o início. Que pontos de interseção entre o dentro-fora do palco são também pontos de permanência e âncoras da dramaturgia do Coletivo, construída a partir de fragmentos ficcionais, memórias e atualidades?

Havia um terceiro chão a ser mapeado, onde se cruzavam as urgências da macropolítica - lutas deflagradas nos últimos anos e que tomam as ruas no Brasil hoje - e as resistências da micropolítica que, neste recorte, podemos entender como um estado em arte. Uma procura por dizer com e desde a poética em cena. Estado para construir um fazer que é tão mais singular quanto mais arejado forem seus contornos:

[...] a idéia de subjetividade é aberta, é um todo aberto, ela não está calcada neste modelo de identidade, de interioridade, de uma delimitação, ela é aberta a tudo que é exte- 
rior, ela não tem um centro, ela não tem uma identidade, ela está mais disponível para as forças que a atravessam e a habitam, ou seja, a subjetividade, por definição, está mais aberta aos devires que a tomam, mais aberta a uma multiplicidade que a habitam, mais aberta aos atravessamentos e as multiplicidades que empurram para inúmeros lados (PELBART, 2016, online).

Neste terreno de convivências - postas em cena pelos três performers e por outros corpos materiais - sons e imagens operam entre si movimentos autônomos em estruturas relacionais. Como um objeto composto de elementos indissociáveis, os gestos sonoro-visuais intervêm na fala, na dança, no canto, na luz, na dramaturgia, no tempo de Volume Morto: ritmos aliados à silêncios; vozes em contraponto a escutas; a privação da visão em diálogos com o espaço cênico; o palco sobreposto por movimentos de dança e também pela presença do público, muito próxima. Coisas que, juntas, estabelecem diferentes texturas em cena.

Algo idiomático às texturas é o olhar tridimensional que parecem sugerir. Uma textura não determina uma percepção única acerca do que se fabula durante o espetáculo, mas, sim, abre janelas de escuta. Um volume é sempre algo a ser percebido a partir de diferentes dimensões e perspectivas, afinal.

Uma mala é arrastada, uma voz de mulher canta. Um peixe anda de costas, faz som mecânico. As rodas que correm, da mala e da mesa, o zíper que abre. Um projetor faz som de ar e de máquina. Imagens da mineradora, as imagens fazem um som mudo, de dor, de amor? Sons de bem longe, vestígios afetivos. Uma piscina e uma bomba. Bomba de ar. Bombas em toda parte lá fora. Há polícia aqui dentro, sim. Há um rio que morre. Uma lona que se abre, tantos sons, violência tamanha, água para todo lado. Três histórias em vida, outras em memória. Vozes de homens, em cena, em locução, na mata. Chove. Respira. Chove. Uma garrafa de água é um fio que pulsa, também. Faixas de composição, sons concretos. Do aqüífero, camadas de voz, subterrâneos. "Qual a cor da minha pele?" Pensar o tempo do silêncio, ausência não é esvaziamento. Propor subtrações: de trilhas sonoras, de sons reproduzidos - os escapes em cena são a linha mais potente do dizer. O som dos pés no chão.

\section{Pausa}

Entrar em uma história é um movimento cuidadoso. É sobre estabelecer proximidades, reunir-se com um "reservatório de possíveis". Envolver as sonoridades de objetos pessoais do Coletivo e de objetos dos trabalhos anteriores instaurou no processo sonoro de Volume Morto a ação de trans-criar e de criarmos juntos. Estes objetos tiveram, neste contexto, suas naturezas subvertidas para as cenas, mudaram de lugar no mundo, em sua função de objetos cotidianos.

Propor os sons em uma relação emancipada com as materialidades cênicas - corpos orgânicos e inorgânicos - presentes visualmente ou manifestos como memória indelével das histórias em fragmento levadas à público - instaurou um pensamento acerca dos sons - em dissociação ou em contrapontos com as imagens vistas pelos olhos. E também acerca da imaginação - a possibilidade de criar espaços de imagens abertas e momentos de suspensão na relação direta entre olhar e escuta. Como uma fermata, esta figura musical que sustenta o som vibrando no ar por um tempo determinado, não por uma mensuração exata e fixa, mas, sim, pela experiência sensível de uma duração.

Ampliando a idéia de terreno - elemento chão, a carne da terra - perceber as vozes ancestrais de um espaço-terreiro trouxe a busca por acomodar uma sobreposição de memórias, entender um lugar poético para estas narrativas. A voz de uma companhia siderúrgica foi atualizada por sons de objetos não presentes em cena naquele instante, mas que soam como instrumentos musicais em outros momentos do espetáculo - um deslocamento temporal. A voz de um homem do "povo da floresta" a soar junto com uma chuva que se modula, pouco a pouco, em uma trama de fala e sonoridades dicotômicas semanticamente. Uma voz feminina com o mesmo texto, em camadas, cria timbres e vocalidades da composição aquática. Por exemplo.

Em Volume Morto não há um tempo de cena exato, a ser cumprido irremediavelmente, quer quanto aos sons, quer quanto às imagens e movimentos no espaço. Há margens de improviso por parte dos performers e da diretora. Está, em performance, a presença de uma singularidade do encontro, que faz ecoar atravessamentos do instante ao mesmo tempo em que protocolos cênicos sustentem tais variações.

A escolha por um projeto sonoro que prioriza os gestos acústicos produzidos em tempo real e, no qual, as faixas sonoras são operadas em cena, instaura a noção de tempo presente como lugar de ação. Lugar este que aproxima do palco, em sentidos múltiplos, os trabalhos desenvolvidos pelo Coletivo Líquida Ação em espaços públicos até então.

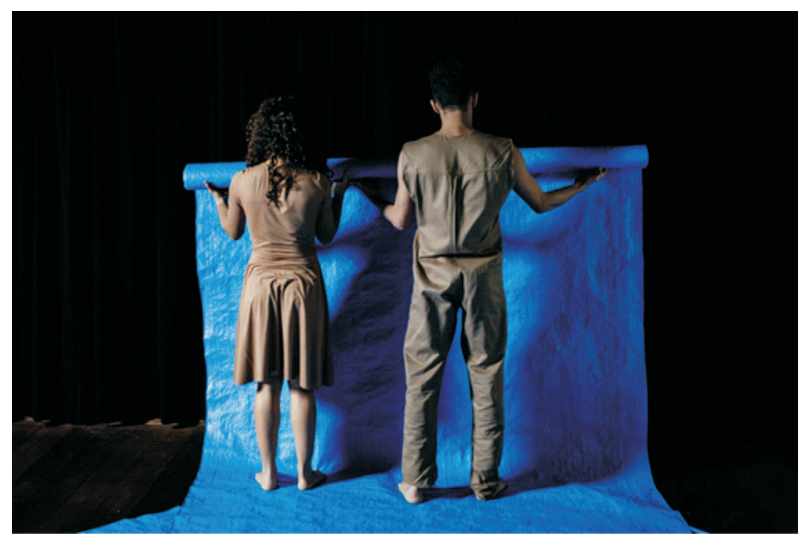

Volume Morto/ Sesc Copacabana 2016. Foto: Cícero Rodrigues. 


\section{Referências}

GUATTARI, F.; ROLNIK, S. Micropolitica: cartografias do desejo. Rio de Janeiro: Vozes, 2005.

PELBART, P. P. Um reservatório de possíveis em nós. 20 out. 2016. Disponível em: <https://laboratoriodesensibilidades. wordpress.com/2016/10/20/um-reservatorio-depossiveis-em-nos/>. Acesso em: 28 out. 2016.

RANCIÈRE, J. O espectador emancipado. São Paulo: Martins Fontes, 2017.

REINACH, F. Volume morto ou vivo? O Estadão, 22 mar. 2014. Disponível em: <http://sao-paulo.estadao.com.br/ noticias/geral,volume-morto-ou-vivo-imp-, 1143746>. Acesso em: 16 jun. 2016.

Recebido em: 16 de novembro de 2016 Aceito em: 23 de junho de 2017 